\title{
Welfare Measures When Agents Can Learn: A Unifying Theory
}

\author{
Jinhua Zhao Catherine L. Kling ${ }^{1}$
}

January 15,2008

\footnotetext{
${ }^{1}$ The authors are Associate Professor and Professor in the Department of Economics, Iowa State University, respectively. We thank seminar participants at the 2004 ASSA Annual Meetings in San Diego, two anonymous referees, and Leonardo Felli (the editor) for their helpful comments. We are responsible for all remaining errors and omissions. Please address correspondence to: Jinhua Zhao, Department of Economics, Heady Hall, Iowa State University, Ames, IA 50011. Voice: 515-294-5857; Fax: 515-294-0221; Email: jzhao@iastate.edu.
} 


\begin{abstract}
We extend Graham's (1981, AER, 715-725) welfare analysis under uncertainty to a dynamic environment where the agent can delay and obtain information to reduce the uncertainty. Our analysis yields a dynamic willingness to pay (WTP) locus that unifies the distinct concepts of option price, dynamic WTP, commitment costs, and quasi-option value. Option price corresponds to the ex ante WTP when the agent ignores the learning opportunity, and dynamic WTP is the value when this opportunity is recognized. The commitment cost is the difference between option price and dynamic WTP, which is also the annualized and monetized quasi-option value. The dynamic locus shows that there is an added value of state contingent contracts because such contracts allow trading among agents with heterogeneous degrees of access to future information and delay opportunities. An example highlights the potential for these welfare effects to be significant. We also show that making quasi-option value adjustments in project analysis, when project values are obtained through nonmarket methods, could result in double counting of quasi-option values.
\end{abstract}

JEL: D61, H40, Q51 
Hicksian compensating and equivalent variation (CV and EV) are standard tools for measuring the welfare effect of a price or quantity change and, in addition to being "exact" measures, they possess the valuable feature of being interpretable as either the maximum willingness-to-pay (WTP) or minimum willingness-to-accept (WTA) for the considered change 1 These tools (or approximations based on Marshallian measures)2 have supported an extensive and influential body of analyses with which economists have been able to inform public policy decisions covering almost the entire spectrum of economic issues.

While the static CV and EV measures of Hicks provide adequate tools for many welfare assessments, they are derived under conditions of perfect certainty making them inappropriate for situations where key variables are stochastic. Prompted by Weisbrod (1964)'s seminal ideas, a number of authors have contributed to the development of welfare measures that incorporate the appropriate risk premia (Cichetti and Freeman (1971), Schmalensee (1972), Smith (1987a, 1987b, and 1983), among others). The analogs to the static CV and EV measures are "option prices" or ex ante compensating and equivalent variation (Helms (1985)) and can be interpreted as ex ante WTP or WTA under uncertainty, depending upon the direction of change.

Option prices have become the core concepts in modern welfare economics, and have provided the tools for a spectrum of policy analyses in many branches of economics, such as trade, public economics, environmental economics, innovation and technology adoption, marketing, etc. An important theoretical refinement was developed by Graham (1981) who demonstrates that option prices are a special case of a set of state dependent payments such that the payments are equal in all states and are therefore contractible ex ante. He constructs a complete WTP locus along which ex ante expected utility is held constant, but ex post payments are state dependent. Cameron and Englin (1997) provide an empirical representation of a complete WTP locus for recreational

\footnotetext{
${ }^{1}$ Strictly speaking the measures associated with a quantity change are compensating and equivalent surplus (Randall and Stoll (1980)), although this distinction is often ignored in the literature and will be throughout this paper as well.

${ }^{2}$ We abstract from the substantial body of literature relating Marshallian consumer surplus to the Hicksian measures throughout this paper, though we note that there are Marshallian counterparts to most of the concepts we discuss. For complete treatment of the Hicksian/Marshallian relationships see Willig (1976), Willig (1978), Bockstael and McConnell (1993), and Just, Heuth and Schmitz (2004).
} 
angling.

While option prices and the WTP locus provide the tools to analyze welfare under uncertainty in a static framework, many decision environments are inherently dynamic. Zhao and Kling (2004) show that under conditions of uncertainty, future information and irreversibility, the equivalence between $\mathrm{CV} / \mathrm{EV}$ and $\mathrm{WTP} / \mathrm{WTA}$ breaks down. The appropriate ex ante welfare measure in this case is the dynamic willingness to pay, which contains both the static welfare measure of CV as well as a dynamic component termed "commitment cost." The dynamic WTP measure is closely related to the concept of quasi-option value (QOV), as developed by Arrow and Fisher (1974) and Henry (1974). The QOV framework alters the decision rule of when to invest in a project by requiring the benefits of a project to exceed both the costs and the lost option value 3 The dynamic WTP, on the other hand, flips the question and asks the maximum an agent is willing to pay now for such a project. The emphasis of the QOV framework is on the decision rule itself under conditions of uncertainty and irreversibility, while the dynamic WTP addresses the appropriate welfare measure under these conditions.

Similar to the extension of option price to the WTP locus by Graham (1981), in this paper we extend the dynamic WTP of Zhao and Kling (2004) to a dynamic WTP locus by allowing ex post state contingent payments. In addition, we provide a unifying theory of the complete set of static and dynamic welfare concepts developed in the economics literature. In particular, we demonstrate that the static Hicksian measures of $\mathrm{CV}$ or EV, the ex ante welfare measures of option price, and the dynamic willingness to pay measure can all be described by points along the locus. In other words, they are all special cases of the more general dynamic locus. The dynamic locus further demonstrates how these concepts are related to each other, and the assumptions needed for each concept to be the appropriate welfare measure for use in an economic analysis.

The dynamic WTP locus provides the relevant welfare measures under two conditions: (i) new information is expected in the future that reduces the uncertainties about the net benefits of the

\footnotetext{
${ }^{3}$ Conrad (1980), Fisher and Hanemann (1986), and Hanemann (1989) further demonstrate that QOV can be interpreted as the conditional value of information.
} 
project, and (ii) ex post risk sharing mechanisms exist to allow for state-contingent payments. A great many public (and private) decisions must be made under precisely these conditions. Uncertainty and future information is ubiquitous, e.g., in cases of climate change policy, development of new drugs and vaccines, biodiversity, biotechnology, urban planning, regulatory design, evaluation of new technologies, etc. Each of these examples shares in common the fact that a decision is made now (whether to sign a climate change treaty, whether to allow the sale of a new drug, whether to build a new mall) when there is substantial uncertainty in at least one of the key features of the decision problem (the rate of climate change, the risk of unintended drug reactions, the demand for mall facilities) and more information can be expected in the future that could reduce this uncertainty (new climate models, studies of drug efficacy, improved demand estimates) 4

Further, in addition to typical private risk sharing mechanisms such as insurance, there is prevalent risk sharing induced by other private mechanisms as well as public policies. A common form of risk sharing in private markets is the use of money back guarantees which insure uncertain private good purchasers that if the good should turn out to be less valuable to them than initially supposed, they will be allowed to recoup their losses (less of course transaction costs associated with returning the good). Governments also routinely provide ex post compensation via tax relief and/or direct payments to individuals when the realization of uncertainty results in losses for part of a population. For example, disaster payments have a long history after weather related events such as drought, floods, or storms for agricultural products (Glauber and Collins (2002)) and damage to public and private infrastructure (Garrett and Sobel (2003)). We illustrate through an example how such policies result in de facto state contingent payments and risk sharing.

Our second contribution is to study the aggregation of individual welfare when learning is possible, based on the dynamic WTP locus. Graham (1981) argues that when a complete contingent claims market and/or insurance is available, agents with heterogeneous risk preferences can achieve higher welfare levels via risk sharing, and thus the simple summation of individuals' option prices,

\footnotetext{
${ }^{4}$ Note also that all examples contain irreversibilities: lost output from lower energy consumption cannot be regained, lives lost due to the absence of the drug are permanent, and it is costly to raze a mall once built.
} 
which excludes this kind of risk sharing, can underestimate the true aggregate welfare of a project. Based on the dynamic WTP locus, we show that even when individuals hold the same risk preferences, they can still benefit from state contingent compensation if they differ in their discount rates and/or the amount of new information available to each in the future. Essentially, future information changes how each individual values payment in each state of nature, thereby creating opportunities for trading. Our analysis shows that government or private mechanisms of risk sharing could significantly enhance the value of a project, especially when future learning is possible among the agents. Moreover, the welfare gains from trading due to informational heterogeneity is not subject to the criticisms of Graham's locus based on preference differences (e.g., Mendelsohn and Strang (1984) and Ready (1995)). We use a concrete example of valuing a rebuilding project after a natural disaster to illustrate possible magnitudes of welfare gains from state contingent trading. The example also shows that this kind of trading is practicable.

Third, we explicitly establish the relationship between the dynamic WTP for, and the QOV associated with, investing in a project. While Zhao and Kling (2004) suggest that the concepts are related, the exact relationship is developed here. Based on the relationship, we argue that if values of an irreversible project are estimated based on stated preference techniques and if the subjects have already incorporated the uncertain and irreversible nature of the project in their answers, then QOV should not be part of the optimal decision problem. In this case, the dynamic WTP values reported by the subjects have already incorporated the QOV of the project. This observation has important implications for cost benefit analysis and decision making using nonmarket valuation methods.

The paper is organized as follows. We set up a general model of welfare measurement and derive the dynamic WTP locus in Section 1. In Section 2, we describe how state contingent payments are made possible by public policies and elaborate with an example. We then show how valuations of agents with different prospects of future information could be aggregated through contracts for state-contingent trading. Next we impose specific preferences and information structure in the 
example to illustrate the efficiency gain and practicality of such trading. In Section 3, we establish formally the relationship between the dynamic WTP and QOV. We discuss the implications of our results for welfare measurement and decision making in Section 4, and conclude the paper in Section 5 ,

\section{A General Model of Welfare Measurement}

For concreteness, we model the valuation of a public good for which a market does not exist. Private good valuation using market signals can be derived in a similar but simpler fashion. Consider an agent's decision about how much to pay to obtain more of a public good, e.g., an environmental amenity. Let $U(x, y, \theta)$ be her utility function, where $x$ is the quantity of the public good, $y$ is the quantity of a composite good, the price of which is normalized to one, and $\theta$ is a parameter which affects the marginal utility of $x$. For an environmental good such as a national park, $\theta$ may reflect a feature of the ecosystem such as the air quality, wildlife diversity and population sizes, or access to facilities. Alternatively, $\theta$ may reflect uncertainty in the consumer's own preferences or situation: whether a promotion comes through, more children are born, or a friend who enjoys rock climbing moves away. Currently (period one) the good is provided at level $x_{0}$, and the proposal is to increase it to level $x_{1}>x_{0}$. We assume that $x$ and $y$ are normal goods, $U(\cdot)$ is twice continuously differentiable in all its arguments, and $U_{x \theta}>0$ (i.e., a higher $\theta$ indicates a higher marginal utility of $x)$.

Let $m$ be the agent's (constant) per period income. Since good $x$ is a public good for which a market does not exist, the agent spends all of her income on $y$ and obtains utility $U\left(x_{0}, m, \theta\right)$. Note that since $y$ is a single composite good priced at 1 , the utility function $U(\cdot)$ is the same as the indirect utility function. For simplicity, we assume away consumption smoothing across periods; that is, per period income $m$ cannot be shifted across periods. We discuss the implications of this assumption later.

Currently the agent does not know the value of $\theta$, only knowing that it is distributed on 
$\Theta \equiv\left\{\theta_{1}, \ldots, \theta_{I}\right\}$ with the probability of $\theta=\theta_{i}$ being $h_{i}>0$, and without loss of generality, with $\theta_{1} \leq \theta_{2} \leq \cdots \leq \theta_{I}$. She will be able to learn more about the value of $\theta$ at the beginning of the next period. Specifically, she will be able to observe a signal, $s \in \mathcal{S} \subseteq \mathcal{R}$, that is correlated with $\theta$. For example, if $\theta$ describes the air quality of a national park, the signal may represent whether a nearby factory adopts stricter pollution control measures. Let $h_{i}^{s}, i=1, \ldots, I$, be the posterior probabilities of $\theta$ after observing a particular signal $s$. The posterior is derived in the Bayesian fashion from the prior distribution $\left\{h_{i}, i=1, \ldots I\right\}$ and the densities of the signal distribution conditional on the values of $\theta$. We assume that the signals are informative: $\left\{h_{i}^{s}, i=1, \ldots, I, s \in \mathcal{S}\right\}$ is more informative about $\theta$ than $\left\{h_{i}, i=1, \ldots, I\right\}$ in the sense of Blackwell $(1951,1953) 5$ The signals may be completely informative, in which case the agent gains complete knowledge about $\theta$ in period two. For ease of description, we assume that the signal density function satisfies the monotone-likelihood ratio property, so that the higher the value of $s$, the higher the posterior of $\theta$ in the sense of first degree stochastic dominance.

For analytical simplicity, we assume that the project (raising $x_{0}$ to $x_{1}$ ) takes one period to finish, and the true value of $\theta$ will be known immediately after the project is completed 6 For instance, after a national park is built and opened, visitors obtain much more information about the air quality by visiting the park 7 The timeline of her decision is as follows. In period one, the agent is presented with an opportunity to purchase the public good $\left(x_{1}\right)$ at a certain price which is payable in all future periods once the project is finished. If she decides to purchase $x_{1}$ now, $x_{1}$ will become available in period two at which time the true value of $\theta$ is observed and the agent starts to pay the previously agreed upon price. Alternatively, she can wait until period two to decide whether to buy, after observing signal $s$. If then she decides to purchase, $x_{1}$ will become available in period three at which time she observes $\theta$ and begins payment for the project. Of course, in

\footnotetext{
${ }^{5}$ That is, an agent making decisions on purchasing $x$ achieves a higher expected utility level with the signal service than without the signals. Equivalently, in the terminology of Marschak and Miyasawa (1968), information about $\theta$ without the signals can be obtained by garbling the information about $\theta$ with the signals.

${ }^{6}$ Our results still hold even if the resolution of uncertainty is not complete. As long as finishing the projects brings more information, we could simply define the states $\Theta$ as this set of information.

${ }^{7}$ In this setup, if the project is delayed, full information about $\theta$, which is possible only at the conclusion of the project, is subsequently delayed as well.
} 
this case she does not enjoy the services of $x_{1}$ in period two. If in period two she decides not to purchase (based on the observed signal $s$ ), additional public good is not provided.

Since the payment is made after the project is finished and $\theta$ is observed, in the spirit of Graham (1981), we consider state contingent payments: let $\boldsymbol{p}=\left(p_{1}, \ldots, p_{I}\right)^{\prime} \in \mathcal{R}^{I}$ be an $I$-dimensional vector of WTP payments, where $p_{i}$ is the payment when $\theta_{i}$ is realized. Suppose first that the agent cannot wait to learn about $\theta$ before making a decision or simply ignores the potential learning opportunities, i.e., she decides on her WTP based on the current information. Then her (per period) state-contingent WTP vectors are given by

$$
\mathcal{P}^{n} \equiv\left\{\boldsymbol{P}^{n} \in \mathcal{R}^{I}, \text { s.t. } \sum_{i=1}^{I} h_{i} U\left(x_{0}, m, \theta_{i}\right) / r=\sum_{i=1}^{I} h_{i} U\left(x_{1}, m-P_{i}^{n}, \theta_{i}\right) / r\right\},
$$

where $r$ is her discount rate, $\boldsymbol{P}^{n}=\left(P_{1}^{n}, \ldots, P_{I}^{n}\right)^{\prime}$ is a WTP vector when there is no learning, and $\mathcal{P}^{n} \subset \mathcal{R}^{I}$ is the set of such WTP vectors. If she decides not to purchase $x_{1}$, she enjoys $x_{0}$ forever, and if she decides to purchase $x_{1}$, then starting in period two when the project is finished, she enjoys $x_{1}$ while making payment $\boldsymbol{P}^{n}$. The equation within the brackets shows the expected present values of the payoffs associated with the two decisions starting period two (because the expected payoffs are the same in period one: $\left.E_{\theta} U\left(x_{0}, m, \theta\right)\right)$. Thus, each $\boldsymbol{P}^{n}$ represents a combination of state dependent payments that equate the expected value of assuring the higher level of the good, $x_{1}$, with the expected value of not buying the good. The set $\mathcal{P}^{n}$ defines Graham's WTP locus in the $\mathcal{R}^{I}$ space, with each vector $\boldsymbol{P}^{n}$ being a point on the locus. When these payments are not state dependent (or are equal in every state), and therefore could be collected ex ante, there is a unique value of payment which equals the option price (Helms (1985), Schmalensee (1972), Cichetti and Freeman (1971), and Ready (1995)). In Figure 1, we plot a typical WTP locus, represented by the bold curve, when there are two possible states: $\Theta=\left\{\theta_{1}, \theta_{2}\right\}$.

When the payments are not equal across the different states, a payment schedule $\boldsymbol{P}^{n}$ can be agreed upon ex ante with the actual payments being made ex post. These payments can occur either as a lump sum or annual payments. In particular, the agent may commit to paying a state contingent lump sum amount $\boldsymbol{P}^{n} / r$ for $x_{1}$ as soon as the project is finished and the value of $\theta$ is 


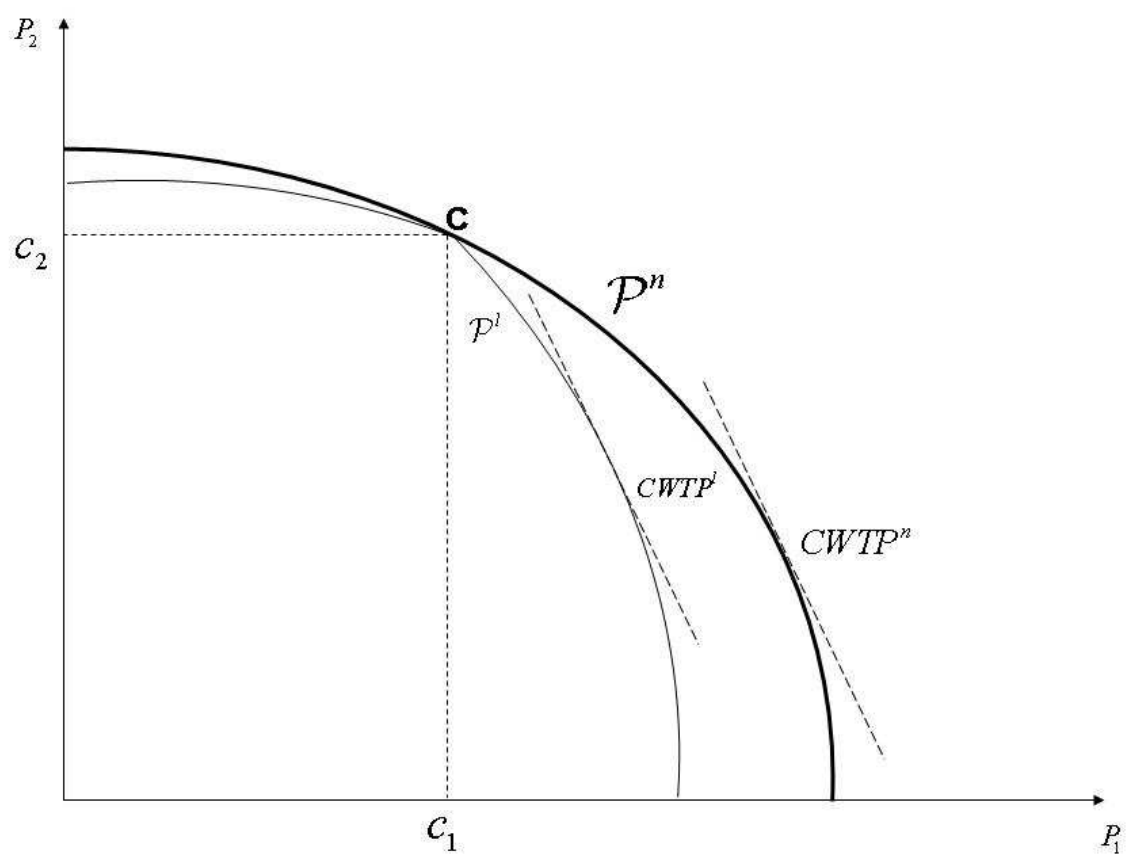

Figure 1: WTP Loci With And Without Learning

realized. In this case, $\boldsymbol{P}^{n}$ is the annualized payment of the lump sum. Alternatively the agent may commit ex ante to pay $\boldsymbol{P}^{n}$ in every period in the future. For clarity, we follow the latter interpretation throughout the paper.

To derive the dynamic WTP locus with learning, we explicitly consider the timeline of information: suppose the agent can wait until period two for more information on $\theta$ before deciding whether to purchase $x_{1}$. We seek to determine payments $\boldsymbol{p} \in \mathcal{R}^{I}$ that leave the agent indifferent between waiting to make the decision until period two and committing to the purchase today. If the agent decides to purchase $x_{1}$ in the current period, her expected payoff is

$$
V_{0}(\boldsymbol{p})=\sum_{i=1}^{I} h_{i} U\left(x_{0}, m, \theta_{i}\right)+\sum_{i=1}^{I} h_{i} U\left(x_{1}, m-p_{i}, \theta_{i}\right) / r
$$

In this case, starting in period two she is assured of the good but must pay $p_{i}$ for each realization of $\theta_{i}$ in every period. If she waits until the second period to decide, she will observe the signal, say, 
$s$, and she will pay $\boldsymbol{p}$ if and only if

$$
\sum_{i=1}^{I} h_{i}^{s} U\left(x_{1}, m-p_{i}, \theta_{i}\right) \geq \sum_{i=1}^{I} h_{i}^{s} U\left(x_{0}, m, \theta_{i}\right) .
$$

Thus, if $s$ is low relative to $\boldsymbol{p}$, the agent can choose not to purchase the good, thereby avoiding the "mistake" of committing to purchase $x_{1}$ when its expected surplus conditional on $s$ is less than the price. Of course, waiting also has a cost: if $s$ turns out to be sufficiently high, the agent could have purchased $x_{1}$ in period one and started to enjoy the valuable public good in the second period, instead of having to wait until period three to consume $x_{1}$.

Let $\mathcal{S}_{p}(\boldsymbol{p}) \subseteq \mathcal{S}$ be such that (3) is satisfied if and only if $s \in \mathcal{S}_{p}(\boldsymbol{p})$, and let $\mathcal{S}_{n p}(\boldsymbol{p})=\mathcal{S} \backslash \mathcal{S}_{p}(\boldsymbol{p})$. That is, $\mathcal{S}_{p}(\boldsymbol{p})$ contains (sufficiently high) signals $s$, which, after being observed, would result in the agent being willing to pay $\boldsymbol{p}$, and $\mathcal{S}_{n p}(\boldsymbol{p})$ contains the values of $s$ under which the agent would not be willing to pay for the project. Then her expected payoff of not purchasing now and waiting to decide until the second period is

$$
\begin{aligned}
V_{1}(\boldsymbol{p})= & \left(1+\frac{1}{1+r}\right) \sum_{i=1}^{I} h_{i} U\left(x_{0}, m, \theta_{i}\right) \\
& +\frac{1}{(1+r) r}\left[E_{s \in \mathcal{S}_{p}(\boldsymbol{p})} \sum_{j=1}^{I} h_{j}^{s} U\left(x_{1}, m-p_{j}, \theta_{j}\right)+E_{s \in \mathcal{S}_{n p}(\boldsymbol{p})} \sum_{j=1}^{I} h_{j}^{s} U\left(x_{0}, m, \theta_{j}\right)\right] \\
= & \left(1+\frac{1}{r}\right) \sum_{i=1}^{I} h_{i} U\left(x_{0}, m, \theta_{i}\right) / r+\frac{1}{(1+r) r} W_{p}\left(x_{1}, x_{0}, m, \boldsymbol{p}\right),
\end{aligned}
$$

where

$$
W_{p}\left(x_{1}, x_{0}, m, \boldsymbol{p}\right)=E_{s \in \mathcal{S}_{p}(\boldsymbol{p})}\left\{\sum_{j=1}^{I} h_{j}^{s}\left[U\left(x_{1}, m-p_{j}, \theta_{j}\right)-U\left(x_{0}, m, \theta_{j}\right)\right]\right\} \geq 0
$$

represents the value of being able to wait and observe the signal, and $E_{s \in \mathcal{S}_{p}(\boldsymbol{p})}$ represents the expectation over $s$ on the set $\mathcal{S}_{p}(\boldsymbol{p})$. The first equality in (4) follows since the agent can only consume $x_{0}$ in the first two periods, and the second equality follows from the fact that $\sum_{i} h_{i} U\left(x_{0}, m, \theta_{i}\right)=$ $E_{s \in \mathcal{S}} \sum_{j} h_{j}^{s} U\left(x_{0}, m, \theta_{j}\right)$. If the agent decides not to purchase $x_{1}$ in period one, she still has the option of making a decision with better information in period two. Thus, in (4) the payoff includes not only the expected benefit of not purchasing $x_{1}$, but also the additional value of the delay option, $W_{p} /(r(1+r))$. 
We can see from (2) and (4) that both $V_{0}(\boldsymbol{p})$ and $V_{1}(\boldsymbol{p})$ are monotone decreasing in $\boldsymbol{p}$. In the case of $V_{1}(\boldsymbol{p})$, as the required payment for $x_{1}$ increases, there will be more values of $s$ such that the agent will decide not to purchase $x_{1}$, and thus the set $\mathcal{S}_{p}(\boldsymbol{p})$ gets smaller. Since she can decide not to purchase $x_{1}$ as $\boldsymbol{p}$ increases, her loss from the higher $\boldsymbol{p}$ is lower than it would be without this opportunity to delay. We can also show that both $V_{0}(\boldsymbol{p})$ and $V_{1}(\boldsymbol{p})$ are continuous in $\boldsymbol{p} 8$ In addition, $V_{0}>V_{1}$ at $\boldsymbol{p}=(0, \ldots, 0)^{\prime}$ and $V_{0}<V_{1}$ at $\boldsymbol{p}=(\infty, \ldots, \infty)^{\prime}$ : with positive time preference, the agent will always prefer to enjoy $x_{1}$ earlier if it costs nothing and so will always purchase the good in the first period. If it is extremely costly, she is better off never buying $x_{1}$. Then, vectors $\boldsymbol{p} \in \mathcal{R}^{I}$ exist that equate $V_{0}$ and $V_{1}$, and the set of such vectors is

$$
\mathcal{P}^{l} \equiv\left\{\boldsymbol{P}^{l} \in \mathcal{R}^{I}, \text { s.t. } \sum_{i=1}^{I} h_{i} U\left(x_{0}, m, \theta_{i}\right)=\sum_{i=1}^{I} h_{i} U\left(x_{1}, m-P_{i}^{l}, \theta_{i}\right)-\beta W_{p}\left(x_{1}, x_{0}, m, \boldsymbol{P}^{l}\right)\right\},
$$

where $\beta=1 / 1+r$ is the discount factor. The set of vectors $\mathcal{P}^{l}$ represent the WTP locus when the opportunity to delay and learn is present: we term this the "dynamic WTP locus." A particular vector, $\boldsymbol{P}^{l} \in \mathcal{P}^{l}$, represents a point on this locus 9

To study the relative locations of the two loci, $\mathcal{P}^{n}$ and $\mathcal{P}^{l}$, let $\boldsymbol{c}$ be the vector of ex post state contingent $\mathrm{CV}$, representing the payment vector such that the agent is indifferent between purchasing $x_{1}$ and the status quo given any realization of $\theta$ :

$$
U\left(x_{0}, m, \theta_{i}\right)=U\left(x_{1}, m-c_{i}, \theta_{i}\right), \quad \forall i=1, \ldots, I .
$$

Point $\boldsymbol{c}$ is the "certainty point" in the language of Graham (1981). From (1) and (7), and as noted by Graham (1981), it is obvious that $c \in \mathcal{P}^{n}$. Further, from (15) - (7), we know $c \in \mathcal{P}^{l}$ : facing price vector $\boldsymbol{c}$ in period two, the agent is always indifferent between buying $x_{1}$ and waiting, regardless of the signal $s$. The term in the square bracket of (5) is zero, and thus $W_{p}\left(x_{1}, x_{0}, m, \boldsymbol{p}\right)=0$ and $c \in \mathcal{P}^{l}$. Therefore, the two loci, $\mathcal{P}^{n}$ and $\mathcal{P}^{l}$, meet at $\boldsymbol{c}$. Next we show that they can only meet at $\boldsymbol{c}$.

\footnotetext{
${ }^{8}$ From (2), $V_{0}(\cdot)$ is continuous in $\boldsymbol{p}$ since $U(\cdot)$ is continuous in $m$. To show that $V_{1}(\cdot)$ is continuous, we only need to argue that this is so even when an infinitesimal change in $\boldsymbol{p}$ leads to a discrete change in $\mathcal{S}_{p}$ and $\mathcal{S}_{n p}$ (this is possible when the signal space $\mathcal{S}$ is discrete). Suppose a small increase in $\boldsymbol{p}$ causes one signal, say $\hat{s}$, to move from $\mathcal{S}_{p}$ to $\mathcal{S}_{n p}$. From the definitions of $\mathcal{S}_{p}$ and $\mathcal{S}_{n p}$ and (3), we see that at the margin, (3) must be satisfied as an equality when $s=\hat{s}$. That is, $V_{1}(\cdot)$ is still smooth despite a discrete change in $\mathcal{S}_{p}$ and $\mathcal{S}_{n p}$.

${ }^{9}$ We can show that the dynamic locus is unique, since $V_{1}(\boldsymbol{p})-V_{0}(\boldsymbol{p})$ crosses zero only once.
} 
Proposition 1 The WTP locus under learning, $\mathcal{P}^{l}$, cannot lie above that without learning, $\mathcal{P}^{n}$. Further, they meet only at the certainty point $\boldsymbol{c}$.

The proof is given in Appendix A. Figure 1 illustrates the relative positions of the loci. The two loci, $\mathcal{P}^{n}$ and $\mathcal{P}^{l}$, share the point c, but elsewhere $\mathcal{P}^{l}$ lies inside and to the left of $\mathcal{P}^{n}$.

If the agent foregoes the opportunity of obtaining more information and thus making a better informed decision, she must be "compensated" for her lost learning opportunity by paying less for $x_{1}$ in the current period. When there is the opportunity to delay and learn, the agent's base utility level — the expected utility associated with not committing to the purchase today — is higher than it otherwise would be because she retains the option of purchasing the good in the future. In this scenario, there is a higher cost of purchasing the good today than when the delay-and-learn alternative is not available; thus, the expected net benefit of the current purchase commitment is lower. The only exception is at point $\boldsymbol{c}$ : at this point, new information about $\theta$ does not lead to new decisions regarding whether or not the agent should pay for $x_{1}$. That is, the new information is useless, as it provides no value in reaching the optimal decision.

The dynamic locus is not differentiable at $\boldsymbol{c}$; Figure 1 shows the kink at $\boldsymbol{c}$ when there are two states of nature. The intuition is that on different sides of $\boldsymbol{c}$, the sets of signals for purchasing $x_{1}, \mathcal{S}_{p}(\boldsymbol{p})$, are different (in fact, complements of each other). From (6), the rates of substitution between $p_{1}$ and $p_{2}$ in $W_{p}\left(x_{1}, x_{0}, m, \boldsymbol{p}\right)$ are then different along the two sides. To see this, suppose the signals are completely informative, e.g., $\mathcal{S}=\left\{s_{1}, s_{2}\right\}, h_{1}^{s_{1}}=1$, and $h_{1}^{s_{2}}=0$. That is, when $s_{1}$ (or $s_{2}$ ) is observed, the agent knows that the state will be $\theta_{1}$ (or $\theta_{2}$ ) for sure. If $\boldsymbol{p}$ is to the lower right of $\boldsymbol{c}$ (i.e., $p_{1}>c_{1}$ and $p_{2}<c_{2}$ ), the agent pays for the improvement when $s_{2}$ is observed, but not when $s_{1}$ is observed, and the plan is reversed if the proposed payment $\boldsymbol{p}$ is to the upper left of c. The discrete change in the contingent plans leads to the nondifferentiability of the locus at $\boldsymbol{c}$. In particular, from (6) and that to the upper left of $\boldsymbol{c}$ is $(1-\beta) \frac{h_{1} U_{y}\left(x_{1}, m-c_{1}, \theta_{1}\right)}{h_{2} U_{y}\left(x_{1}, m-c_{2}, \theta_{2}\right)}$.

As the signals become more informative, the agent will have a higher incentive to wait for the 
signals before committing to a payment $\boldsymbol{p}$. Thus, she is less willing to pay $\boldsymbol{p}$ now and forego the opportunity of knowing $s$. Consequently, her dynamic WTP locus shifts down. The following Proposition establishes this result, and in the proof (Appendix A), we provide the formal definition of and more discussion about more informative signals.

Proposition 2 As the signals become more informative in the sense of Blackwell (1951, 1953), the dynamic locus $\mathcal{P}^{l}$ shifts downwards, except at point $\boldsymbol{c}$.

Before completing our discussion of the dynamic WTP locus, we consider the case in which a complete state contingent claims market exists, and let $\boldsymbol{w}=\left(w_{1}, \ldots, w_{I}\right)$ be the $I$-dimensional vector of prices of the state contingent claims. Since $w_{i}$ is the price of "one dollar in state $\theta_{i}$," the total cost for a given WTP function $\boldsymbol{p}$ is $\boldsymbol{w} \boldsymbol{p}$. Define the (maximum) complete market WTP without learning as $C W T P^{n} \equiv \max _{\boldsymbol{p} \in \mathcal{P}^{n}} \boldsymbol{w} \boldsymbol{p}$, and, with learning, as $C W T P^{l} \equiv \max _{\boldsymbol{p} \in \mathcal{P}^{l}} \boldsymbol{w} \boldsymbol{p}$. Figure 1 shows the determination of the two WTP measures relative to the two loci.

As argued by Graham (1981), the complete market WTPs are the appropriate welfare measures when the contingencies are competitively priced. If a complete market exists, the difference

$C W T P^{n}-C W T P^{l}$ is the complete market commitment cost, $C C_{p}^{*}$, which measures the effect of being able to delay and learn on the value of the public good. A decision to purchase the good now commits the agent to pay for $x_{1}$ regardless of future signals about $\theta . C C_{p}^{*}$ measures the cost of doing so when a complete market exists. Then the welfare measure of Graham (1981), $C W T P^{n}$, has to be adjusted for this cost of commitment. Obviously, $C C_{p}^{*}$ is increasing in the informativeness of the signals.

\section{Aggregation of Individual Welfare Measures}

An important motivation for Graham (1981) to introduce the WTP locus is to illustrate how individual welfare measures can be aggregated depending on the availability of complete contingent claims or actuarially fair insurance markets. Like the Hicksian compensation criterion, if the winners 
of a project can more than compensate the losers, the project is considered welfare improving. When state contingent compensation is possible, i.e., when the amount of transfer among the winners and losers can be made to depend on the realization of $\theta$, the simple summation of individuals' option prices may be an understatement of the true aggregate welfare of a project 10 Instead, the aggregate WTP locus should be used to determine the welfare effect of the project.

Risk sharing or state contingent compensation may be achieved either through markets or by the government. Examples of risk sharing through markets include insurance (discussed extensively in the literature) and moneyback guarantees 11 While not normally viewed as such, governments also have tools for risk sharing via tax systems where those who gain from a public project can be taxed ex post to compensate those who lose. To the extent that who gains and who loses are state contingent, such a tax system serves as a risk sharing mechanism. In fact, governments routinely compensate those who lose from public projects, sometimes as a result of the political lobbying process or of random events (such as weather disasters). General examples include property tax relief for residential or commercial real estate projects that do not generate the revenue ex post that they expected ex ante or the infusion of government support for crop failures or flooded houses after a weather disaster. Government entities also set many user fees which can be adjusted on a state contingent basis, for instance park entrance and museum fees, roadtolls, registration and license fees, etc. Even the mortgage bailouts being considered at the time of the writing of this paper can be seen as an ex post compensation for the "failure" of the mortgage market resulting from the state contingent outcome of reduced house price appreciation.

To illustrate how such government policies lead to state contingent trading, consider a stylized example of a decision to undertake a public project to rebuild a flood devastated area (such as a section of New Orleans post Katrina). The economist's task is to assess the expected benefit of such a public good project (e.g., to be compared with the expected cost in a cost-benefit study).

\footnotetext{
${ }^{10}$ As has been observed, such state contingent compensation can be agreed upon with ex ante contracts that specify the transfer for the future once $\theta$ is realized, and the actual compensation occurs ex post.

${ }^{11}$ As shown in Heiman, McWilliams, Zhao and Zilberman (2002), moneyback guarantees are similar to a financial put option, an instrument for risk sharing and hedging.
} 
For concreteness, imagine that the project under consideration is the fortification of levies and development of public parks and other infrastructure to establish upscale residential areas.

Suppose there are two states of nature: $\theta=\theta_{2}$ if the project is successful in revitalizing the area, and $\theta=\theta_{1}$ if the project fails to revitalize the area. Success would come from the re-establishment of strong demand for housing in the area with lack of success represented by the failure of the re-establishment of a vital neighborhood. Suppose the government will set the property tax at $\tau$ if the project succeeds and will reduce the property tax by $\xi$ if the project fails. The levels of $\tau$ and $\xi$ may or may not be linked. If the budget needs to be balanced ex ante and there are no external subsidies, $h_{2} \tau=h_{1} \xi$ so that $\tau / \xi=h_{1} / h_{2}$. However, $\tau / \xi$ might not be equal to $h_{1} / h_{2}$ if there are subsidies, for instance, from the federal government or if additional tax revenues need to be generated from the scheme. Finally, suppose the tax changes are rationally expected by potential residents (while we do not imagine that the government would announce its intention to lower property tax rates if the project is less successful than anticipated, we assume residents rationally anticipate this result from past observation of ex post bailouts after weather catastrophes and large scale accidents).

To illustrate how the tax policy enables state contingent trading, consider an agent who will purchase a house at price $v$. Facing the uncertainty in $\theta$, we know that at the completion of the project her tax burden will be raised by $\tau v$ with probability $h_{2}$ and will be reduced by $\xi v$ with probability $h_{1}$. Thus, ex post, by varying the value of $v$, her income (or payment) in the two states can be traded at the ratio of $\tau / \xi$. For instance, a higher $v$ (i.e., purchasing a more expensive property) enables the individual to increase her income in state $\theta_{1}$ by a larger amount (by, of course, reducing her income in state $\theta_{2}$ ). Conversely, if the agent sells a property, the negative $v$ effectively raises her income in state $\theta_{2}$ while reducing her income in state $\theta_{1}$.

In this example, the level of trading might have to be discrete given the usually discrete values of $v$ (e.g., the lack of ability to sell half of a house). However, for other projects such as cleaning up a lake, there might be much more room for incremental trading. For instance, consider a lake 
cleanup project and suppose that if the project is successful, there will be higher usage fees of the lake as well as higher property tax in the local area, while the fees and tax will be reduced if the project fails. Then an agent can vary the level of trading $v$ by changing the size of property to purchase/sell, the amount of time share in a local resort, the kind of recreation boat to bring to the lake, or even the number of visits to the lake, etc.

Our example can be expanded to allow for heterogenous impacts of the public project on different agents. A flood protection project, if successful, may protect one part of a city while hurting another (for instance by diverting water to the latter area or through economic connections between the two areas). Then it is possible that in state $\theta_{1}$, the property tax increases in one area but decreases in the other, while in state $\theta_{2}$, the tax changes are reversed for both areas. There are thus more state contingent trading opportunities, since now agents can trade by investing in either or both areas.

The example also demonstrates the similarity of policy-induced state-contingent trading to that induced by private insurance. The trading ratio in an insurance market is affected by the actuarial fairness of the insurance contract, while the ratio in our example is affected by the budget constraints of the government. As noted earlier, money back guarantees are also an important form of risk sharing in private markets. In this case, the "insurance" is provided by the firm that sells the product to the consumers who may be uncertain about the level of enjoyment they will get from the product. By insuring that the consumers can return the good for a full refund, firms cut off the downside risk to consumers, thereby increasing their (dynamic) WTP. Of course, the price at which products with money back guarantees are sold reflects this cost, as shown in Heiman et al (2002).

Public policy induced state contingent trading offers strong support for welfare measures based on Graham's locus. Further, recognizing that WTP is dynamically formed creates new importance for state contingent trading: there are real ex post welfare gains from such trading due to agent heterogeneities in time preferences and future learning opportunities. That is, even when individuals 
have the same risk preferences, there are still positive benefits from ex post compensation schemes that transfer income between individuals due to differences in their discount rates and the amount of new information. If individuals have different rates of time preference or differing opportunities to learn, a point on the aggregate dynamic WTP locus will correspond to different points on the individual dynamic WTP loci. The decision maker, through ex post payments, effectively allows the individuals to "trade" their different time preferences and future information. As a result, the aggregate WTP locus is more likely to contain points that pass an ex post potential Pareto test than an ex ante test.

To illustrate how agents can "trade" these heterogeneities through state contingent payments, we continue with our example of rebuilding after Katrina. Suppose there are two groups of agents, denoted as $\mathcal{N}_{1}$ and $\mathcal{N}_{2}$, identical except for their access to future information. In particular, suppose agents in group one, $\mathcal{N}_{1}$, live near the proposed rebuild project, perhaps in a nearby township, and can relatively easily learn in the next period how likely the project will succeed in building a vibrant residential and commercial area. In contrast, agents in group two, $\mathcal{N}_{2}$, live in another city, perhaps having moved there after the hurricane, and consequently have less direct sources of information about the potential success of the project. To simplify the analysis, let us assume that group one agents in the next period will receive completely informative signals, e.g., $\mathcal{S}_{1}=\Theta$, while agents in group two will not learn at all, e.g., $\mathcal{S}_{2}=\emptyset$.

Figure 2 illustrates the two agent groups' WTP loci and the aggregate locus. Since an agent in $\mathcal{N}_{1}$ can learn, her WTP locus, $\mathcal{P}_{1}^{l}$, lies below that of an agent in group two, $\mathcal{P}_{2}^{l}$. Since their preferences are identical otherwise, $\mathcal{P}_{1}^{l}$ and $\mathcal{P}_{2}^{l}$ coincide at the certainty point $\boldsymbol{c}$. For a group two agent, the slope (or more precisely, the absolute value of the slope) at any point $\boldsymbol{p}^{2}=\left(p_{1}^{2}, p_{2}^{2}\right)$ on her WTP locus is simply the ratio of the marginal utilities of income, weighted by the respective probabilities (cf. (1)):

$$
\frac{h_{1} U_{y}\left(x_{1}, m-p_{1}^{2}, \theta_{1}\right)}{h_{2} U_{y}\left(x_{1}, m-p_{2}^{2}, \theta_{2}\right)} .
$$

For an agent in $\mathcal{N}_{1}$, the slope at a point $\boldsymbol{p}^{1}=\left(p_{1}^{1}, p_{2}^{1}\right)$ on her locus depends on the position of $\boldsymbol{p}^{1}$ 
relative to $\boldsymbol{c}$. Suppose $\boldsymbol{p}^{1}$ is to the lower right of $\boldsymbol{c}$. If the agent waits until period two, she will pay for the public good (i.e., vote for the rebuild project) if $\theta_{2}$ is realized (since $p_{2}^{1}<c_{2}$ ), and will not if $\theta_{1}$ is realized (since $p_{1}^{1}>c_{1}$ ). From (6), the locus is given by

$$
\sum_{i=1}^{2} h_{i} U\left(x_{1}, m-p_{i}^{1}, \theta_{i}\right)-\beta h_{2}\left[U\left(x_{1}, m-p_{2}^{1}, \theta_{2}\right)-U\left(x_{0}, m, \theta_{2}\right)\right]=\sum_{i=1}^{2} h_{i} U\left(x_{0}, m, \theta_{i}\right),
$$

and the slope at $\boldsymbol{p}^{1}$ is

$$
\frac{1}{1-\beta} \frac{h_{1} U_{y}\left(x_{1}, m-p_{1}^{1}, \theta_{1}\right)}{h_{2} U_{y}\left(x_{1}, m-p_{2}^{1}, \theta_{2}\right)}
$$

Thus, the opportunity to learn raises the slope at $\boldsymbol{p}^{1}$. In other words, if the payment in state $\theta_{1}$, $p_{1}^{1}$, increases, $p_{2}^{1}$ has to decrease by a larger amount to make the individual indifferent. From (9), changes in $\boldsymbol{p}^{1}$ affect the payoffs of not only purchasing the public good now, but also not purchasing now and waiting. Since the agent purchases the good only in state $\theta_{2}$, a lower payment in this state (i.e., a lower $p_{2}^{1}$ ) raises the payoff of both purchasing now and waiting, while a higher $p_{1}^{1}$ reduces the payoff of purchasing now only. Consequently, on the dynamic locus, to compensate for a higher $p_{1}^{1}$, a larger reduction in $p_{2}^{1}$ is needed, resulting in a higher slope of the locus.

More intuitively, given the delay-and-learn option, agent one is more reluctant in period one to agree to pay a higher price in state $\theta_{1}$. Since $p_{1}^{1}$ is too high, the agent could simply decide to wait for the signal, thereby avoiding paying the higher price: if state $\theta_{1}$ is indeed realized, the agent will not pay for the public good because $p_{1}^{1}>c_{1}$, the $\mathrm{CV}$ in state $\theta_{1}$. To induce her to agree to buy now (i.e., to keep the agent on the same dynamic locus), the price $p_{2}^{1}$ must be reduced more than that required by the weighted marginal rate of substitution in (8).

Therefore, even though the two individuals have the same utility functions, differences in their learning opportunities lead to a divergence between their valuation of the state contingent payments. As illustrated in Figure 2, point $B$ on the aggregate locus is obtained by summing up $B_{1}$ and $B_{2}$. In this case, the agent in group one values payment in state $\theta_{1}$ relatively more than the agent in group two. Thus, efficient aggregation of their payments involves group one agents paying less than group two agents in state $\theta_{1}$, and more in state $\theta_{2}$. Group one agents obtain payment from group 
two agents in state $\theta_{1}$ and return the favor in state $\theta_{2}$. Ex post trading thus allows group two agents to benefit from group one's access to future information.

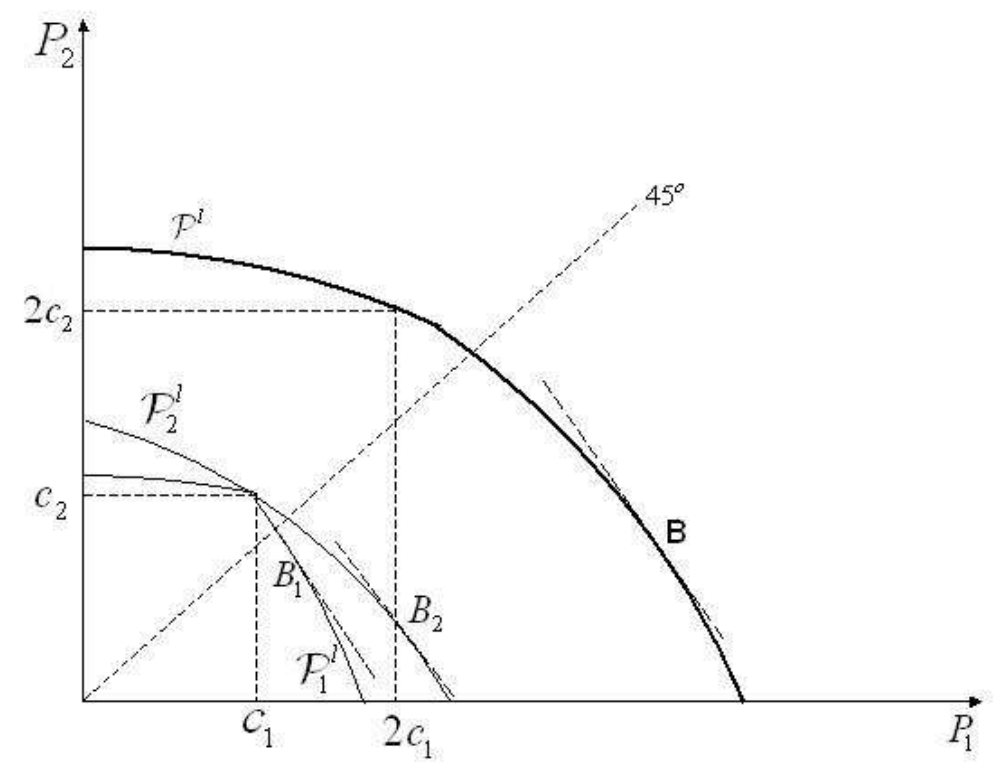

Figure 2: Aggregation of Individual WTP Loci

Similarly, if a group one agent's payment contract $\boldsymbol{p}^{1}$ is to the upper left of $\boldsymbol{c}$, the slope of her dynamic locus is

$$
(1-\beta) \frac{h_{1} U_{y}\left(x_{1}, m-p_{1}^{1}, \theta_{1}\right)}{h_{2} U_{y}\left(x_{1}, m-p_{2}^{1}, \theta_{2}\right)},
$$

which is lower than that without learning. The reason is that payment in state $\theta_{1}$ is less "valuable" for the agent, since a change in $p_{1}^{1}$ affects the payoffs of both purchasing now and waiting in the same direction, and thus has a less significant effect on the relative payoff of purchasing now. Alternatively, the agent is less willing to pay a higher price in state $\theta_{2}$, because given such a price, she will choose to wait for the signal so as to avoid the higher payment if that state is realized. Again, the payment in state $\theta_{1}, p_{1}^{1}$, has to be reduced more to induce her to pay for the public good in the current period. 
Without state contingent trading, each agent's welfare gain from (or WTP for) the project is given by her option price, which is measured by the intersection of $\mathcal{P}_{1}^{l}$ or $\mathcal{P}_{2}^{l}$ with the $45^{\circ}$ line. However, the slope of $\mathcal{P}_{2}^{l}$ at the $45^{o}$ line is $\frac{h_{1}}{h_{2}}$, while that of $\mathcal{P}_{1}^{l}$ is $\frac{1}{1-\beta} \frac{h_{1}}{h_{2}}$. Thus, as long as there is discounting, the slopes differ and state contingent trading strictly improves the welfare and thus raises aggregate WTP. The next Proposition formally establishes this result.

Proposition 3 Suppose the agents have identical preferences and face common risks. However, agents in group $\mathcal{N}_{1}$ have access to fully informative signals in the next period, while agents in group $\mathcal{N}_{2}$ have no access to future information. Suppose further that a complete contingent claims market exists and $0<\beta<1$. Then state contingent payments strictly improve the welfare of the project relative to state independent payments: $\sum_{k} C W T P_{k}^{l}>\sum_{k} O P_{k}$, where the summation is over the number of agents, $C W T P_{k}^{l}$ is agent $k$ 's WTP with state contingent payments, and $O P_{k}$ is her option price.

For concreteness, let us assume that the utility function is Cobb-Douglas, $U(x, m, \theta)=\ln (m)+$ $0.1 \ln (1+x \theta)$, with $x_{0}=0.5, x_{1}=1, \theta_{1}=0.5, \theta_{2}=1, h_{1}=h_{2}=0.5$, and $\beta=1 / 1.05=0.95$ (i.e., $r=5 \%$ ). We also assume that the annual income of each agent is $m=\$ 50,000$. Figure 3 presents the dynamic WTP loci, where the bold curve is for a group two agent (who cannot learn) and the thin curve is for a group one agent (who can completely learn). The WTP locus for the group two agent is almost linear with a slope close to $-h_{1} / h_{2}=-1$, and that of a group one agent is almost piecewise linear, with slopes being close to $-(1-\beta) h_{1} / h_{2}=-0.048$ and $-h_{1} /(1-\beta) h_{2}=-21$ on the two sides of the certainty point $\boldsymbol{c}$. These slopes can be verified from (81), (10) and (11), with the observation that when $p_{1}$ and $p_{2}$, the payments in the two states, are small relative to income $m, U_{y}\left(x_{1}, m-p_{1}, \theta_{1}\right) / U_{y}\left(x_{1}, m-p_{2}, \theta_{1}\right)$ is close to one.

The option price without learning equals $\$ 1161.31$ while that with complete learning is $\$ 926.86$. The commitment cost, which is the difference between the two option prices, is thus $\$ 234.45$. If the government, as discussed above, provides state contingent trading through tax policies, the value of the project to each group of agents depends on the state contingent price ratio $w_{1} / w_{2}$. Table 
1 presents, for several price ratios, the welfare of the project (or the total WTP under contingent trading) for an agent in each of the two groups, as well as the point on the WTP locus at which the welfare is maximized.

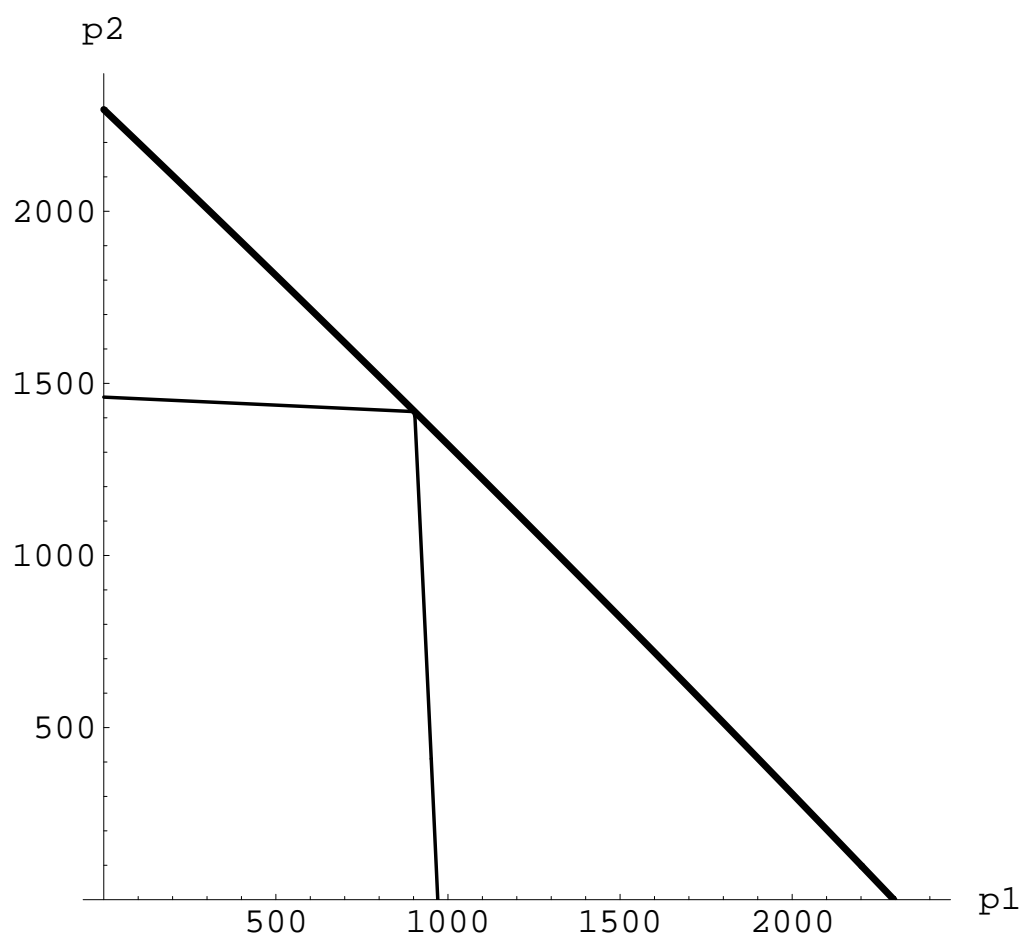

Figure 3: WTP Loci With and Without Learning: Numerical Example

\begin{tabular}{c|cc|c|c}
\hline Price ratio & \multicolumn{2}{|c|}{ Group one: with learning } & \multicolumn{2}{c}{ Group two: no learning } \\
\cline { 2 - 5 }$w_{1} / w_{2}$ & $C W T P^{l}$ & Point of maximization & $C W T P^{n}$ & Point of maximization \\
\hline 0.1 & 1370.74 & $(895.01,1418.31)$ & 2086.82 & $(0,2295.50)$ \\
0.5 & 1246.39 & $(903.35,1417.92)$ & 1530.45 & $(0,2295.67)$ \\
1 & 1160.63 & $(903.35,1417.92)$ & 1161.31 & $(1161.31,1161.31)$ \\
2 & 1074.87 & $(903.35,1417.92)$ & 1530.43 & $(2295.65,0)$ \\
20 & 927.79 & $(905.12,1381.10)$ & 2186.45 & $(2295.77,0)$ \\
\hline
\end{tabular}

Table 1: Expected Welfare Under Different Price Ratios

If tax policies are such that the price ratio $w_{1} / w_{2}=h_{1} / h_{2}=112$ the welfare of the project for a group two agent is $C W T P^{n}=\$ 1161.31$ : the tangency point between her dynamic locus and the

\footnotetext{
${ }^{12}$ As we discussed earlier, this is the case if the local government's budget needs to be balanced ex ante.
} 
contingent price line is at $\left(p_{1}, p_{2}\right)=(1161.31,1161.31)$. That is, if the state contingent claim prices are "fair," the expected welfare of the project under no learning is the same with and without contingent claims trading. However, for a group one agent, the expected welfare of the project is $C W T P^{l}=\$ 1160.63$, much higher than the corresponding option price. The point at which the welfare is maximized occurs at the certainty point $\boldsymbol{c}=(903.348,1417.92)$. Heterogeneity in learning opportunities thus enhances the value of state contingent trading. As the price ratio decreases, the project's value increases for both groups of agents, while as the price ratio increases, the project's value increases only for group two agents.

This simple numerical example demonstrates the potential for sizable welfare differences when project induced sharing occurs. Consider one agent from each of the two groups. With a price ratio of 0.5 , the sum of the CWTP over the two agents is $\$ 2776.84$, which means that the value of sharing is $\$ 688.67$ (recalled that the total option price is $1161.31+926.86=\$ 2088.17$ ), or about $25 \%$ of the total project value. Similarly, at a price ratio of 20 , the sum of the CWTPs is $\$ 3114.24$, resulting in a welfare gain associated with sharing of $\$ 1026.07$. Clearly, differences of this magnitude could mean the difference between a project passing a benefit-cost comparison or not. In the example presented here, failure to include the welfare gains associated with sharing could result in failure to implement a project that is welfare enhancing.

\section{State Independent Payments and Quasi-Option Value}

In the case of a state-independent WTP (where the payment for $x_{1}$ is independent of the realization of $\theta), \boldsymbol{P}^{n}$ defined in (11) reduces to the ex ante compensating variation or option price, denoted as $O^{n}$ and defined by

$$
E_{\theta} U\left(x_{0}, m, \theta\right)=E_{\theta} U\left(x_{1}, m-O^{n}, \theta\right) .
$$

As noted earlier, this is the point on the (static) WTP locus where a 45 degree ray from the origin intersects the locus. Helms (1985) and Schmalensee (1972) demonstrate that under uncertainty 
(and without learning), this is the appropriate welfare measure rather than the ex post expected compensating variation.

However, when the agent can delay and learn, the point on the dynamic WTP locus with equal payments in each state represents the dynamic WTP, which is denoted as $O^{l}$. The dynamic WTP is closely related to the QOV of Arrow and Fisher (1974) and Dixit and Pindyck (1994). To see the correspondence, note that ([6]) can be rewritten as

$$
E_{\theta} U\left(x_{0}, m, \theta\right) / r+Q\left(O^{l}\right)=E_{\theta} U\left(x_{1}, m-O^{l}, \theta\right) / r
$$

where $Q\left(O^{l}\right)=(\beta / r) W_{p}\left(x_{1}, x_{0}, m,\left(O^{l}, O^{l}, \ldots, O^{l}\right)\right)$ is the QOV associated with waiting 13 If the agent decides not to buy $x_{1}$ in the current period, she can still choose to purchase it in the next period. Thus, the expected payoff of not buying today includes both the direct payoff $E_{\theta} U\left(x_{0}, m, \theta\right) / r$ associated with not paying today plus the value of retaining the option to purchase (or not) in the future, measured by $Q\left(O^{l}\right)$.

From Proposition 1, we know $O^{l}<O^{n}$ : the willingness to pay today is lower than the option price. To see this, note that if $O^{l}=O^{n}$, by (12), there exist signals in $\mathcal{S}$ such that the agent will purchase $x_{1}$, or the set $\mathcal{S}_{p}\left(O^{n}\right)=\mathcal{S}_{p}\left(O^{l}\right)$ is nonempty 14 Then (5) implies that $W_{p}\left(x_{1}, x_{0}, m,\left(O^{l}, O^{l}, \ldots, O^{l}\right)\right)>0$, or $Q\left(O^{l}\right)>0$. Thus, if $O^{l}=O^{n}$, (12) and (13) would contradict each other. In order for the agent to "buy" $x_{1}$ in the current period, the "price" of $x_{1}$ has to be lower to compensate for the lost opportunity of obtaining more information. Figure 4 illustrates the relationship between $O^{l}$ and $O^{n}$.

Following Zhao and Kling (2004), we define the commitment cost associated with WTP as $C C=$ $O^{n}-O^{l}$. The commitment cost measures the reduction in the agent's willingness to pay necessary to compensate for the lost opportunity to collect future information and use that information to

\footnotetext{
${ }^{13}$ Strictly speaking, it measures the value of being able to wait and learn more about $\theta$ before making the decision, relative to the scenario where no waiting is allowed. In this sense, it is more similar to the option value concept developed in Dixit and Pindyck (1994). However, the real options literature has typically not distinguished between the QOV of Arrow and Fisher (1974), which is in essence the conditional value of information, and the option value of Dixit and Pindyck (1994). We follow this tradition in this paper.

${ }^{14}$ Otherwise, if $\mathcal{S}_{p}\left(O^{n}\right)=\emptyset$, the definition of $\mathcal{S}_{p}$ implies that $\sum_{i} h_{i}^{s} U\left(x_{1}, m-O^{n}, \theta_{i}\right)<\sum_{i} h_{i}^{s} U\left(x_{0}, m, \theta_{i}\right)$ for all $s \in \mathcal{S}$, which implies that $E_{\theta} U\left(x_{1}, m-O^{n}, \theta\right)<E_{\theta} U\left(x_{0}, m, \theta\right)$, violating (12).
} 


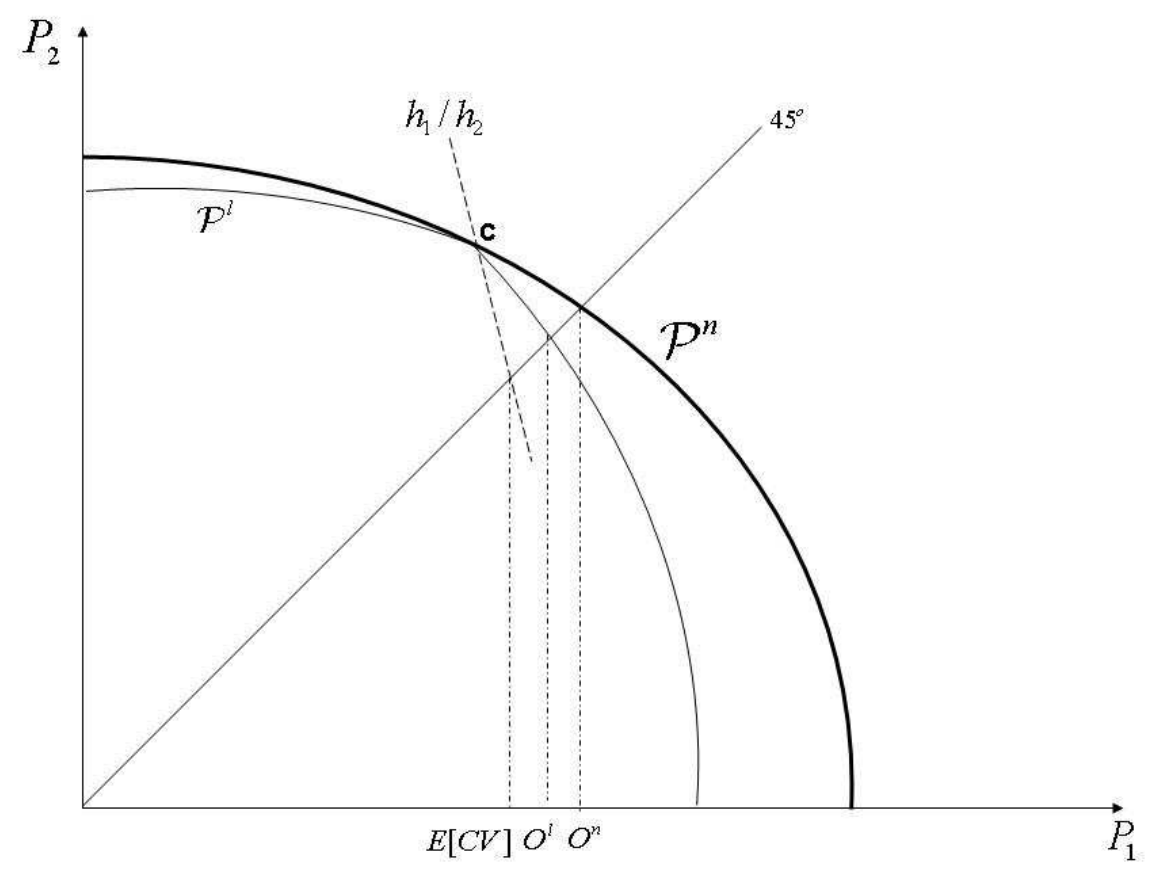

Figure 4: Dynamic WTP and Option Price

make a better decision. It thus represents the opportunity cost of committing to the purchase today. From (12) and (13), we have

$$
E_{\theta} U\left(x_{1}, m-O^{n}, \theta\right)=E_{\theta} U\left(x_{1}, m-O^{n}+C C, \theta\right)-r Q\left(O^{l}\right) .
$$

Since $O^{n}$ is the option price, (14) also illustrates the relationship between option price, QOV, and commitment cost. Applying a Taylor expansion around $m-O^{n}$, we know

$$
C C=\frac{r Q\left(O^{l}\right)}{E_{\theta} U_{m}\left(x_{1}, m-O^{n}, \theta\right)},
$$

when $C C$ is small. Thus, in the neighborhood of $m-O^{n}$, the commitment cost equals the annualized QOV in monetary units. The QOV measures the expected utility of waiting for more information; for the agent to buy in the current period, the lump sum compensation she demands is $Q$ (cf. (13)) ). Of course, this compensation can also come in the form of annual utils of $r Q$. Dividing the annual utils by the (expected) marginal utility of income, we obtain the corresponding annual monetary transfer $r Q / E U_{m}$. This transfer is precisely the price discount the agent will require to forego the 
learning opportunity. It is the commitment cost.

Equation (15) demonstrates the close link between QOV and dynamic welfare measures. Many of the results of the QOV literature can be directly applied to commitment costs. For example, as the signals become more informative, the agent can learn more about $\theta$ by waiting. Thus the option value of waiting, $Q$, rises, and so does the commitment cost $C C$. Likewise, as the discount factor, $\beta$, increases, the cost of waiting (delayed consumption of $x_{1}$ ) falls. Again, $Q$ and thus $C C$ increases. In summary,

Summary 1 The dynamic WTP, $O^{l}$, is lower than the option price $O^{n}$ by a commitment cost that equals the annualized QOV associated with raising the amount of the public good.

At this point, we discuss the implications of our assumption that there is no intertemporal consumption smoothing. Since the WTP is expressed as per period payments, consumption smoothing occurs in the first period if the agent decides to make a decision now, and occurs for the first and second periods if she decides to wait for more information. If the agent decides to buy $x_{1}$ in the first period, say at price $p$, her consumption of $y$ is $m$ in period one, and is $m-p$ in every period afterwards. Consumption smoothing occurs between period one and later periods; she will thus save some income in period one for consumption later. However, if she decides to wait until period two to buy, her consumption of $y$ is $m$ for the first two periods, and is $m-p$ in every period afterwards. Now she has more room for consumption smoothing: she can save in both periods one and two to increase the consumption of $y$ in later periods. As a result, the expected payoff of waiting, and thus the QOV of waiting, will be higher if consumption smoothing is allowed. From the relationship between $C C_{p}$ and the $\mathrm{QOV}$, we know $C C_{p}$ will be higher. Thus, the assumption of no consumption smoothing reduces the magnitude of the commitment cost. 


\section{Implications for Cost Benefit Analysis}

In this section, we discuss some important implications of our analysis for cost benefit analysis. We first argue that the dynamic loci provide additional reasons for using state contingent contracts in project evaluation. Then we show how recent developments in welfare economics could potentially be "misused," based on the relationship between commitment cost and QOV established above.

\subsection{The Importance of State Contingent Payments}

Our analysis demonstrates the increased importance of risk sharing and state contingent contracts in improving the benefits of public projects when there is heterogeneity among agents in their access to future information and delay opportunities. A well-debated objection to Graham's argument for using state contingent contracts is that if agents have heterogeneous preferences, they should have already shared risk before a public project is undertaken. Using Graham's locus in cost benefit analysis amounts to assuming that the project, in addition to improving the public good, also allows complete risk sharing which is otherwise impossible. Mendelsohn and Strang (1984) showed that if there is complete risk sharing regardless of the project, the marginal utilities of income in different states are always equal, and the WTP locus reduces to a straight line with a slope equal to the probability ratios. Then option price is the appropriate welfare measures for efficiency because all state contingency payments yield the same expected value.

We have two comments about the objections. Private insurance seldom leads to complete state contingent markets. As we discussed in Section 2, many times further state contingent trading is induced by public policies that accompany large scale projects. Welfare evaluation of such projects should take into consideration the effects of such policy induced trading. More fundamentally, these objections to the state contingent locus do not apply in the dynamic setting. From Proposition 3 , even when agents have the same preferences, state contingent payments are still useful for them to share heterogeneous access to future information and delay opportunities. Even if the static WTP locus is a straight line, the dynamic locus is not. Further, since such information and delay are 
relevant only for the proposed project, risk sharing prior to the project does not eliminate the need for state contingent contracts to trade the heterogeneity in information and delay. The project, by introducing possibilities of delay and future information, engenders new trading opportunities which raise the value of state contingent contracts. In other words, the objections to using Graham's locus do not extend to the dynamic locus developed in this paper.

This conclusion is based on the implicit assumption that, except for the state contingent payments, the agents do not have other means of trading their heterogeneity in information and delay. This assumption is likely to be valid in many situations, as agents may differ in their willingness and ability to delay and their uncertainties may be idiosyncratic. In our example in Section 2 , it is hard to imagine opportunities in a market for the two groups of agents to "trade" their different degrees of access to future information. However, gains from state contingent payments accrue to both groups of agents. Unlike the case of insurance, there is no private market independent of the project that can transfer these gains. State contingent contracts engendered by the project then provide the only way for agents to share information and delay opportunities. Therefore,

Summary 2 When agents are heterogeneous in their access to future information and abilities to delay, complete risk sharing among the agents prior to the project does not eliminate the benefits from state contingent contracts. Such contracts allow the agents to share project specific information and delay opportunities.

\subsection{Potential Double Counting of QOVs}

Cost benefit analysis is playing an increasingly important role in project evaluation and government decision making. Two developments in economics over the past two decades are slowly, but significantly, shaping how such analysis is conducted.

The first development, following the seminal work of Fisher, Krutilla and Cicchetti (1972), argues that uncertainty and availability of future information are sufficiently important to warrant special attention in cost benefit analysis and decision making. Historical experience provides strong 
support for their contention. For example, Reisner (1986) documents how ignoring the opportunity for future information contributed to the over-development of water resources in the western US. Further, a number of important government documents have recently called for careful attention to QOVs and learning in project assessment, such as the recent National Academy's report on ecosystem valuation (National Research Council, 2004).

The second development is the rapidly growing reliance on non-market valuation methods in monetizing impacts that are not traded in regular markets, particularly the use of stated preferences or survey methods 15 The highly publicized controversy over the monetary value of the damages caused by Exxon oil spill in Prince William Sound, Alaska prompted the National Oceanic and Atmospheric Administration to form a blue-ribbon panel, specifically to examine the use of stated preference methods in assessing damages in legal proceedings. The committee recommended that such methods continue to be used, albeit with conservative design (Arrow, Solow, Portney, Leamer, Radner and Schuman (1993)). Today, nonmarket methods are increasingly accepted for use in public project assessment and government decision making (see for example U.S. Office of Management and Budget (2003), and U.S. Environmental Protection Agency (2000)).

These two trends raise several questions with regard to the welfare measures developed and discussed in this paper. First, what welfare measures will stated preference methods elicit (option prices or dynamic WTP) and are they the appropriate measures for cost benefit analysis (i.e., those that will support a potential Pareto test)? Second, is there a risk of double counting associated with the use of dynamic WTP measures and the separate inclusion of QOV? If so, how can such errors be ameliorated?

To fix ideas, suppose a government agency is considering a project that improves the water quality at a lake, and to estimate the value of higher water quality levels, it uses nonmarket methods such as contingent valuation surveys to elicitate how the affected population (e.g., residents surrounding the lake) values water quality. In the meantime, there is an ongoing limnological study

\footnotetext{
${ }^{15}$ Assessments of the accuracy of these methods can be found in Cummings and Taylor (1999) and Carson (1997).
} 
of the effects of such a project on the lake ecosystem, e.g, what will happen to water clarity, sediment, and bacteria levels, and the results will be generally available to both the agency and the public. Further, respondents independently know about the ongoing research, and they believe future surveys or referenda are possible. Finally, suppose no mechanisms exist for state contingent payments, so that the appropriate welfare measure is the state independent WTP. In the context of our model, $x_{0}$ and $x_{1}$ measure the project levels (with and without the improvement project) and $\theta$ measures the water qualities associated with the two project levels.

Once the results of the surveys are provided to the decision maker, how should the aggregate WTP be used in recommending a decision: should she compare the present value of the total WTP estimates with the costs of the project and go forward if the difference is positive? A key point of the real options literature is that this kind of comparison between the aggregate option price and the cost is not efficient. Instead, QOV should be incorporated to account for the irreversibility of the project and future information. But, as shown in (15), the monetized QOV is simply the commitment cost, which would have already been incorporated in valuation if it was $O^{l}$ (the dynamic WTP) that was elicitated. Thus the answer depends on whether the elicited WTP values represent the option price or the dynamic WTP which correctly accounts for the lost learning opportunities 16

If the elicited welfare measure is $O^{l}$, there will be no need for additional correction to the decision rule: comparing the present value of the $O^{l}$ values with the cost will yield the correct choice. In fact, were the decision maker to consider QOV in addition to the $O^{l}$ values, she would over-compensate for the QOV. This would amount to the double counting of QOV as the consumer welfare measure would have accounted for the uncertainty and value of information prior to the QOV decision rule adjustment. If instead only option price is elicited, adjustment by the QOV is needed for the efficient decision. Thus,

Summary 3 For projects with uncertainty, irreversibility and future information, if survey respon-

\footnotetext{
${ }^{16}$ This assumes of course that the decision maker wants to employ a potential Pareto improvement test to make the decision, irrespective of distributional or other concerns.
} 
dents have already incorporated the effects of delay and future information in their reported WTP values, the elicited welfare measure is the dynamic WTP, and the decision on the project should not be adjusted for the QOV. If however, the elicited welfare measure is the option price, the decision should be adjusted for the QOV associated with the project.

Now, what measure is a stated preference survey likely to elicit? Suppose the respondent accurately understands the degree of uncertainty concerning the benefits of the preserved area and realizes that there is an opportunity to delay and learn. She will then use $O^{l}$ to respond to the stated preference scenario, i.e., the survey elicits the dynamic WTP. Suppose however that the respondent does not understand (or believe) that there is a chance to delay and (mistakenly) assumes that there is an impending development risk. Then the value reported will correspond to option price. The point is that respondents' beliefs about uncertainty and the opportunity to delay and learn will affect the formation of their WTP values. These beliefs do not necessarily match the true situation, and the decision maker needs to understand the beliefs and thus the nature of the elicitated values, in order to make necessary adjustments in the cost-benefit decision rules.

If the respondents' beliefs match the truth, the standard rule of directly comparing the elicitated aggregate WTP values with the project cost yields efficient decisions. Thus, a key lesson is that stated preference practitioners may need to work hard to convey the true uncertainties and abilities to delay projects to respondents. More fundamentally, it may also be useful to elicit from survey respondents their beliefs about these uncertainties and delay abilities to observe whether the perceptions being used by respondents accords to that of the decision maker.

\section{Conclusions}

In this paper, we develop the dynamic WTP locus, which extends Graham's WTP locus to a dynamic framework where the agent can delay and obtain more information about the underlying uncertainty. The dynamic WTP locus unifies the distinctive concepts of option price, dynamic WTP, commitment costs, and quasi-option value. In particular, option price corresponds to the $e x$ 
ante WTP when the agent ignores the learning opportunity, and dynamic WTP is the value when this opportunity is recognized. The commitment cost is the difference between OP and dynamic WTP, which is also the annualized and monetized QOV.

The dynamic locus has important implications for welfare analysis and decision making. It highlights the added value of using state contingent contracts in project evaluation and implementation, because such contracts allow trading among agents of heterogeneous access to future information and delay opportunities. Even when state contingent trading is available through private insurance prior to the project, our analysis still provides a case for using public projects to redistribute contingent benefits among the affected population. Essentially, state contingent contracts allow the agents to share the returns from project specific information and delay opportunities. Private insurance markets cannot do so.

Our model also calls for better understanding of the nature of the WTP values elicitated by nonmarket valuation methods, and the respondents' beliefs regarding future information and delay. Depending on the beliefs, the elicitated values could be option price, or dynamic WTP. Making quasi-option value adjustments to a decision rule, as argued by the existing literature, is appropriate only when option price is elicitated. If, however, the delay and learn option is fully recognized by the respondents, the elicitated value is the dynamic WTP, which has already incorporated the QOV. Making an additional QOV adjustment will result in double counting of this value.

\section{A Model Details}

Proof of Proposition 1. Let $\mathcal{R}^{I}\left(\leq \mathcal{P}^{n}\right) \equiv\left\{\boldsymbol{p} \in \mathcal{R}^{I}\right.$, s.t. $\exists \boldsymbol{P}^{n} \in \mathcal{P}^{n}$ with $\left.\boldsymbol{p} \leq \boldsymbol{P}^{n}\right\}$ be the half space below locus $\mathcal{P}^{n}$. Since $U\left(x, m-p_{i}, \theta_{i}\right)$ is decreasing in $p_{i}$, we know from (11) that $\mathcal{R}^{I}\left(\leq \mathcal{P}^{n}\right)=\left\{\boldsymbol{p} \in \mathcal{R}^{I}\right.$, s.t. $\left.\sum_{i=1}^{I} h_{i} U\left(x_{0}, m, \theta_{i}\right) \leq \sum_{i=1}^{I} h_{i} U\left(x_{1}, m-p_{i}, \theta_{i}\right)\right\}$. Immediately, from (6), $\mathcal{P}^{l} \subseteq \mathcal{R}^{I}\left(\leq \mathcal{P}^{n}\right)$ because $W_{p}\left(x_{1}, x_{0}, m, \boldsymbol{p}\right)$ is nonnegative from the definition of $\mathcal{S}_{p}$. Thus, $\mathcal{P}^{l}$ lies below $\mathcal{P}^{n}$. Further, $\boldsymbol{P}^{l}$ lies strictly below $\mathcal{P}^{n}$ (i.e., $\boldsymbol{P}^{l} \in \mathcal{R}^{I}\left(\leq \mathcal{P}^{n}\right)$ and $\left.\boldsymbol{P}^{l} \notin \mathcal{P}^{n}\right)$ if $\mathcal{S}_{p}(\boldsymbol{p}) \neq \emptyset$ for all $\boldsymbol{p} \in \boldsymbol{P}^{l}$. 
Since we already showed that $c \in \mathcal{P}^{n}$ and $c \in \mathcal{P}^{l}$, we only need to show that $\mathcal{P}^{n}$ and $\mathcal{P}^{l}$ cannot meet at other points. Suppose instead that there exists a $\boldsymbol{p} \in \mathcal{P}^{n} \cap \mathcal{P}^{l}$ and $\boldsymbol{p} \neq \boldsymbol{c}$. Again, (1) and (6) imply that $W_{p}\left(x_{1}, x_{0}, m, \boldsymbol{p}\right)=0$, or $U\left(x_{1}, m-p_{i}, \theta_{i}\right) \leq U\left(x_{0}, m, \theta_{i}\right), \forall i$. Combining this with (11), it must be that $U\left(x_{1}, m-p_{i}, \theta_{i}\right)=U\left(x_{0}, m, \theta_{i}\right), \forall i$, or $\boldsymbol{p}=\boldsymbol{c}$.

Proof of Proposition 2, Consider two sets of signals or two information services: $\mathcal{S}=$ $\left\{s_{i}, i=1, \ldots, S\right\}$ and $\mathcal{S}^{\prime}=\left\{s_{i}^{\prime}, i=1, \ldots, S^{\prime}\right\}$, where $S$ and $S^{\prime}$, not necessarily the same, indicate the number of possible signals in the two services respectively.

Let $\Pi$ be an $I \times S$ matrix of conditional probabilities of the signals in $\mathcal{S}$, with the $i j^{\text {th }}$ element being $\pi_{i j}=\operatorname{Prob}\left(s=s_{j} \mid \theta=\theta_{i}\right), i=1, \ldots, I, j=1, \ldots, S$. Given prior distribution $\boldsymbol{h}=$ $\left(h_{1}, \ldots, h_{I}\right)$ of the state $\theta$, we know that the marginal distribution of the signals are given by $\boldsymbol{g}=\left(g_{1}, \ldots, g_{S}\right)$ with $g_{j}=\sum_{i=1}^{I} \pi_{i j} h_{i}$. The posterior probabilities of $\theta$ given $s_{j} \in \mathcal{S}$, denoted as $\boldsymbol{h}^{j}=\left(h_{1}^{j}, \ldots, h_{I}^{j}\right)$, is given by the Bayes rule: $h_{i}^{j}=\pi_{i j} h_{i} / g_{j}$. Ex ante, any signal in $\mathcal{S}$ is possible to materialize. We let an $S \times I$ matrix

$$
H=\left[\begin{array}{c}
\boldsymbol{h}^{1} \\
\boldsymbol{h}^{2} \\
\vdots \\
\boldsymbol{h}^{S}
\end{array}\right]
$$

be the posterior matrix of $\theta$ under information service $\mathcal{S}$, with the $j i^{\text {th }}$ element of $H$ being $h_{i}^{j}=$ $\operatorname{Prob}\left(\theta=\theta_{i} \mid s=s_{j}\right)$. Similarly, we define $\Pi^{\prime}, \boldsymbol{g}^{\prime}$ and $H^{\prime}$ for information service $\mathcal{S}^{\prime}$.

Based on Blackwell (1951, 1953), as summarized in Kihlstrom (1984), we provide a definition for the notion that "signal service $\mathcal{S}$ is more informative than $\mathcal{S}^{\prime}$."

Definition 1 Information service $\mathcal{S}$ is more informative than $\mathcal{S}^{\prime}$ if the agent's expected payoff in (4) is higher under $\mathcal{S}$ than under $\mathcal{S}^{\prime}$. That is,

$$
W_{p}\left(x_{1}, x_{0}, m, \boldsymbol{p} \mid \mathcal{S}\right) \geq W_{p}\left(x_{1}, x_{0}, m, \boldsymbol{p} \mid \mathcal{S}^{\prime}\right)
$$

where $W_{p}(\cdot)$ is given in (5). 
Consider the dynamic WTP locus $\mathcal{P}^{l^{\prime}}$ given in (6) under information service $\mathcal{S}^{\prime}$. Given any price $\boldsymbol{p}$, Definition 1 implies that the option value $W_{p}$ is higher under $\mathcal{S}$ than under $\mathcal{S}^{\prime}$. Thus, at any price $\boldsymbol{p} \in \mathcal{P}^{l^{\prime}}$,

$$
\sum_{i=1}^{I} h_{i} U\left(x_{0}, m, \theta_{i}\right) \geq \sum_{i=1}^{I} h_{i} U\left(x_{1}, m-p_{i}, \theta_{i}\right)-\beta W_{p}\left(x_{1}, x_{0}, m, \boldsymbol{p}\right) .
$$

Since the right hand side is decreasing in $\boldsymbol{p}$ (see the discussion preceding (6)), to restore equality price $\boldsymbol{p}$ must decrease. Thus, the dynamic WTP locus under $\mathcal{S}, \mathcal{P}^{l}$, cannot lie above $\mathcal{P}^{l^{\prime}}$. The two loci meet at prices $\boldsymbol{p}=\boldsymbol{c}$, because $W_{p}(\cdot \mid \mathcal{S})=W_{p}\left(\cdot \mid \mathcal{S}^{\prime}\right)=0$ when $\boldsymbol{p}=\boldsymbol{c}$.

Further Discussion on More Informative Signals. To further illustrate the intuition of Proposition 2 and to provide a sufficient condition for $\mathcal{P}^{l}$ to lie strictly below $\mathcal{P}^{l^{\prime}}$ (except at point c), consider another definition of more informative signals that is equivalent to Definition 1 (the equivalence was established by Blackwell (1951, 1953)):

Definition 2 Information service $\mathcal{S}$ is more informative than $\mathcal{S}^{\prime}$ if there exists an $S^{\prime} \times S$ Markov matrix $D, 17$ such that

$$
H^{\prime}=D H, \quad \text { and } \quad \boldsymbol{g}=\boldsymbol{g}^{\prime} D
$$

We expand $H^{\prime}=D H$ in (18) using (16) and obtain

$$
\boldsymbol{h}^{i}=\sum_{k=1}^{S} d_{i k} \boldsymbol{h}^{k}, \quad i=1, \ldots, S^{\prime}
$$

Since vector $\boldsymbol{h}^{\prime i}$ describes the posterior distribution of $\theta$ given signal $s_{i}^{\prime} \in \mathcal{S}^{\prime}$, (19) implies that any such vector under $\mathcal{S}^{\prime}$ can be expressed as a convex combination of posterior vectors under information service $\mathcal{S}$. Each $\boldsymbol{h}^{i}$ lies in the convex hull of $\left\{\boldsymbol{h}^{k}, k=1, \ldots, S\right\}$. Thus, signals in $\mathcal{S}^{\prime}$ can be interpreted as "interim signals:" observing $s_{i}^{\prime} \in \mathcal{S}^{\prime}$, we obtain "updated" information (relative to the marginal distribution $\boldsymbol{g}$ ) about the distribution of signals $s \in \mathcal{S}$, which is given by $\left(d_{i 1}, \ldots, d_{i S}\right)$. Further information about $\theta$ is then obtained after observing a signal in $\mathcal{S}$.

Let $\Phi^{k}(\boldsymbol{p}) \equiv \sum_{j=1}^{I} h_{j}^{k}\left[U\left(x_{1}, m-p_{j}, \theta_{j}\right)-U\left(x_{0}, m, \theta_{j}\right)\right]$ measure the expected payoff of purchasing $x_{1}$ after observing signal $s_{k} \in \mathcal{S}$, and let $1(\cdot)$ be an indicator function taking a value of one if its

\footnotetext{
${ }^{17}$ A Markov matrix is one with nonnegative elements in which elements in each row sum to one.
} 
argument is true and zero otherwise. From (5) and (19), we know

$$
\begin{aligned}
W_{p}\left(x_{1}, x_{0}, m, \boldsymbol{p} \mid \mathcal{S}^{\prime}\right) & =E_{s^{\prime} \in \mathcal{S}_{p}^{\prime}(\boldsymbol{p})}\left\{\sum_{j=1}^{I} \sum_{k=1}^{S} d_{s^{\prime} k} h_{j}^{k}\left[U\left(x_{1}, m-p_{j}, \theta_{j}\right)-U\left(x_{0}, m, \theta_{j}\right)\right]\right\} \\
& =E_{s^{\prime} \in \mathcal{S}_{p}^{\prime}(\boldsymbol{p})}\left\{\sum_{k=1}^{S} d_{s^{\prime} k} \sum_{j=1}^{I} h_{j}^{k}\left[U\left(x_{1}, m-p_{j}, \theta_{j}\right)-U\left(x_{0}, m, \theta_{j}\right)\right]\right\} \\
& =\sum_{s^{\prime}=1}^{S^{\prime}} g_{s^{\prime}}^{\prime}\left(\sum_{k=1}^{S} d_{s^{\prime} k} \Phi^{k}(\boldsymbol{p})\right) 1\left(\sum_{k=1}^{S} d_{s^{\prime} k} \Phi^{k}(\boldsymbol{p})\right),
\end{aligned}
$$

where the first equality is obtained by substituting (19) into (5), the second equality follows by changing the order of summation over $j$ and $k$, and the third equality follows from the definition of $\mathcal{S}_{p}$ and $\Phi^{k}$.

Note however that the option value under signal service $\mathcal{S}$ is

$$
\begin{aligned}
W_{p}\left(x_{1}, x_{0}, m, \boldsymbol{p} \mid \mathcal{S}\right) & =\sum_{k=1}^{S} g_{k} \Phi^{k}(\boldsymbol{p}) 1\left(\Phi^{k}(\boldsymbol{p}) \geq 0\right) \\
& =\sum_{k=1}^{S} \sum_{s^{\prime}=1}^{S^{\prime}} g_{s^{\prime}}^{\prime} d_{s^{\prime} k} \Phi^{k} 1\left(\Phi^{k} \geq 0\right) \\
& =\sum_{s^{\prime}=1}^{S^{\prime}} g_{s^{\prime}}^{\prime} \sum_{k=1}^{S} d_{s^{\prime} k} \Phi^{k} 1\left(\Phi^{k} \geq 0\right),
\end{aligned}
$$

where the second equality is obtained after substituting in $\boldsymbol{g}=\boldsymbol{g}^{\prime} D$ (or $g_{k}=\sum s^{\prime} g_{s^{\prime}}^{\prime} d_{s^{\prime} k}$ ) from (18), and the third equality follows from changing the order of summation.

Equations (20) and (21) immediately imply that $W_{p}(\cdot \mid \mathcal{S}) \geq W_{p}\left(\cdot \mid \mathcal{S}^{\prime}\right)$, and the inequality is strict if there exists $s_{k} \in \mathcal{S}$ so that $\Phi^{k}<0$ and $d_{s^{\prime} k} \neq 0$ for some $s^{\prime} \in \mathcal{S}_{p}^{\prime}(\boldsymbol{p})$. If the agent observes $s^{\prime} \in \mathcal{S}_{p}^{\prime}$, her optimal decision is to purchase $x_{1}$. However, if she has access to signals in $\mathcal{S}$, the purchase decision might not be optimal because with probability $d_{s^{\prime} k}>0$, she observes signal $s_{k} \in \mathcal{S}$ for which the expected payoff of purchase, $\Phi^{k}$, is negative.

Proof of Proposition 3 , Let $\left(w_{1}, \ldots, w_{I}\right)$ be the prices of state contingent claims. Then for any agent $k$,

$$
\begin{aligned}
& O P_{k}=C W T P_{k}^{l} \quad \text { if } \quad \frac{w_{i}}{w_{j}}=\frac{h_{i}}{h_{j}} \\
& O P_{k}<C W T P_{k}^{l} \quad \text { if } \quad \frac{w_{i}}{w_{j}} \neq \frac{h_{i}}{h_{j}} .
\end{aligned}
$$


The marginal rate of substitution between any two states $\theta_{i}$ and $\theta_{j}$ is $h_{i} / h_{j}$ for a group two agent and $h_{i} /(1-\beta) h_{j}$ for a group one agent. Since $\beta<1$, we know for any $\left(w_{1}, \ldots, w_{I}\right)$, there always exist agents in either or both groups whose marginal rates of substitution between any two states $\theta_{i}$ and $\theta_{j}$ are different from $w_{i} / w_{j}$. The Proposition then follows from (22).

\section{References}

Arrow, Kenneth J. and Anthony C. Fisher, "Environmental Preservation, Uncertainty, and Irreversibility," Quarterly Journal of Economics, 1974, 88, 312-319.

— , Robert Solow, Paul R. Portney, E. E. Leamer, R. Radner, and E. H. Schuman, "Report of the NOAA Panel on Contingent Valuation," Federal Register, 1993, 58, 4601-4614.

Blackwell, D., "The Comparison of Experiments," in "Proceedings of the Second Berkeley Symposium on Mathematical Statistics and Probability," University of California Press, 1951, pp. 93-102.

_ _ "Equivalent Comparisons of Experiments," Annals of Mathematical Statistics, 1953, 24, 265272 .

Bockstael, Nancy E. and Kenneth E. McConnell, "Public Goods as Characteristics of Nonmarket Commodities," Economic Journal, 1993, 103, 1244-1257.

Cameron, T. and J. Englin, "Welfare Effects of Changes in Environmental Quality under Individual Uncertainty About Use," Rand Journal of Economics, 1997, 28, S45-S70.

Carson, Richard, "Contingent Valuation: Theoretical Advances and Empirical Tests since the NOAA Panel," American Journal of Agricultural Economics, 1997, 79, 1501-1507.

Cichetti, Charles J. and A. Myrick Freeman III, "Option Demand and Consumer Surplus: Further Comment," Quarterly Journal of Economics, 1971, 85, 538-539. 
Conrad, J., "Quasi-Option Value and the Expected Value of Information," Quarterly Journal of Economics, 1980, pp. 813-820.

Cummings, Ronald G. and Laura O. Taylor, "Unbiased Value Estimates for Environmental Goods: A Cheap Talk Design for the Contingent Valuation Method," American Economic Review, 1999, 89, 649-665.

Dixit, Avinash K. and Robert S. Pindyck, Investment Under Uncertainty, Princeton, N.J.: Princeton University Press, 1994.

Fisher, Anthony C. and W. Michael Hanemann, "Option Value and the Extinction of Species," in V. K. Smith, ed., Advances in Applied Micro-Economics, Vol. 4, JAI Press Inc, 1986, pp. 169-190.

_ _ John V. Krutilla, and Charles J. Cicchetti, "The Economics of Environmental Preservation: A Theoretical and Empirical Analysis," American Economic Review, 1972, 62, 605-619.

Garrett, Thomas and Russell Sobel, "The Political Economy of FEMA Disaster Payments," Economic Inquiry, 2003, 41, 496-509.

Glauber, Joseph and Keith Collins, "Crop Insurance, Disaster Assistance, and the Role of the Federal Government in Providing Catastrophic Risk Protection," Agricultural Finance Review, Fall 2002, pp. 81-101.

Graham, Daniel A., "Cost-Benefit Analysis under Uncertainty," American Economic Review, 1981, $71(4), 715-725$.

Hanemann, W. Michael, "Information and the Concept of Option Value," Journal of Environmental Economics and Management, 1989, 16, 23-37.

Heiman, Amir, Bruce McWilliams, Jinhua Zhao, and David Zilberman, "Modeling Money-back Guarantees as Financial Options," Journal of Retailing, 2002, 78, 246-264. 
Helms, L. Jay, "Expected Consumer's Surplus and the Welfare Effects of Price stabilization," International Economic Review, 1985, 26, 603-617.

Henry, Claude, "Investment Decisions Under Uncertainty: The Irreversibility Effect," American Economic Review, 1974, 64, 1006-1012.

Just, R.E., D.L. Heuth, and A. Schmitz, The Welfare Economics of Public Policy: A Practical Approach to Project and Policy Evaluation, Northampton, MA: Edward Elgar, 2004.

Kihlstrom, Richard E., "A "Bayesian" Exposition of Blackwell's Theorem on the Comparison of Experiments," in Marcel Boyer and Richard Kihlstrom, eds., Bayesian Models in Economic Theory, North-Holland, 1984, chapter 2, pp. 13-31.

Marschak, Jacob and Koichi Miyasawa, "Economic Comparability of Information Systems," International Economic Review, 1968, 9, 137-174.

Mendelsohn, Robert and William J. Strang, "Cost-Benefit Analysis Under Uncertainty: Comment," American Economic Review, 1984, 74, 1096-1099.

National Research Council of the National Academies, Water Science and Technology Board, "Valuing Ecosystem Services: Toward Better Environmental Decision Making, Prepublication copy," Technical Report, http://www.nap.edu/books/030909318X/html, 2004.

Randall, Alan and John R. Stoll, "Consumer's Surplus in Commodity Space," American Economic Review, 1980, 70, 449-455.

Ready, Richard C., "Environmental Valuation under Uncertainty," in Daniel W. Bromley, ed., The Handbook of Environmental Economics, Blackwell, 1995, chapter 25, pp. 569-593.

Reisner, Marc P., Cadillac desert : the American West and its disappearing water, New York, N.Y.: Viking, 1986. 
Schmalensee, Richard, "Option Demand and Consumer's Surplus: Valuing Price Changes under Uncertainty," American Economic Review, 1972, 62, 813-824.

Smith, V.K., "Option Value: A Conceptual Overview," Southern Economic Journal, 1983, 49, 654-668.

— , "Nonuse Values in Benefit Cost Analysis," Southern Economic Journal, 1987, 54, 19-26.

, "Uncertainty, Benefit-Cost Analysis and the Treatment of Option Value," Journal of Environmental Economics and Management, 1987, 14, 283-292.

U.S. Environmental Protection Agency, "Guidelines for Preparing Economic Analyses," Technical Report 2000.

U.S. Office of Management and Budget, "Draft 2003 Report to Congreess on the Costs and Benefits of Federal Regulations," Federal Register, 2003, 68, 5492-5527.

Weisbrod, Burton A., "Collective-consumption services of individual consumption goods," Quarterly Journal of Economics, 1964, 78, 471-477.

Willig, R. D., "Consumers' Surplus Without Apology," American Economic Review, 1976, 66, $589-597$.

_ _ "Incremental Consumer's Surplus and Hedonic Price Adjustment," Journal of Economic Theory, 1978, 17, 227-253.

Zhao, Jinhua and Catherine L. Kling, "Willingness-to-Pay, Compensating Variation, and the Cost of Commitment," Economic Inquiry, 2004, 42, 503-517. 